\title{
Primeiro registro de Rhynchopsyllus pulex (Siphonaptera: Tungidae) em Nyctinomops laticaudatus (Chiroptera: Molossidae) no Brasil
}

\author{
First record of Rhynchopsyllus pulex (Siphonaptera: Tungidae) in \\ Nyctinomops laticaudatus (Chiroptera: Molossidae) in Brazil
}

\author{
Sílvia Gonzalez Monteiro ${ }^{1}$ Geder Paulo Herrmann ${ }^{2}$ \\ Franciele Camila Luchese $^{3}$ Vanessa Daniele Mottin $^{3}$
}

\section{RESUMO}

\author{
Descreve-se o parasitismo de Rhynchopsyllus pulex \\ (Siphonaptera: Tungidae) em Nyctinomops laticaudatus \\ (Chiroptera) no município de Santa Maria, Rio Grande do Sul, \\ Brasil. \\ Palavras-chave: Nyctinomops laticaudatus, Rhynchopsyllus \\ pulex, Tungidae, Siphonaptera, morcego, \\ pulgas.
}

- NOTA

\section{ABSTRACT}

The parasitism of Rhynchopsyllus pulex (Siphonaptera: Tungidae) is described in Nyctinomops laticaudatus (Chiroptera) in the county of Santa Maria, Rio Grande do Sul, Brazil.

Key words: Nyctinomops laticaudatus, Rhynchopsyllus pulex, Tungidae, Siphonaptera, bat, flea.

Rhynchopsyllus pulex (Haller, 1880) é uma espécie de pulga pertencente à ordem Siphonaptera, família Tungidae que compreende somente gêneros de pulgas penetrantes ou semipenetrantes.

Estes insetos são parasitas obrigatórios de morcegos, sendo encontradas fêmeas semipenetrantes sobre o hospedeiro, aderidas apenas pelas lacínias da maxila, ficando o tórax e o abdome descobertos. A sua importância é devida à reação inflamatória que induzem, sendo que os orifícios formados por sua introdução no corpo do hospedeiro tornam-se vias de acesso para agentes oportunistas, determinando infecções secundárias (LINARDI \& GUIMARÃES, 2000). Os mesmos autores relatam a sua ocorrência na Argentina, Bolívia, Brasil, Colômbia, Chile, Equador, Peru, e Venezuela. No Brasil, R. pulex foi relatada na Bahia, Minas Gerais, Paraná, Pernambuco, Rio de Janeiro, Santa Catarina e São Paulo, parasitando as seguintes espécies de quirópteros: Eptesicus macrotis, E. velatus, Molussus sp., M. obscurus obscurus, M. perotis, M. rufus, Phyllostoma hastatum e Tadarida macrotis.

Nyctinomops laticaudatus (Geoffroy, 1805) pertence à família Molossidae, possui o lábio superior com dobras, as orelhas são grossas, variando em forma e tamanho, projetando-se geralmente para frente e unidas na base por uma faixa membranosa. Estes morcegos são antrópicos e alimentam-se de insetos no vôo (DVAS, 2004).

Relata-se aqui uma infestação por pulgas da espécie $\boldsymbol{R}$. pulex em morcegos da espécie $\boldsymbol{N}$. laticaudatus. Os morcegos parasitados foram capturados no intuito de pesquisar seus hábitos alimentares no interior de um prédio do campus da Universidade Federal de Santa Maria, por meio de redes especiais para a captura de quirópteros, dispostas próximo ao local de habitação dos mesmos. Durante o exame físico dos animais, observou-se uma infestação por insetos semipenetrantes, os quais provocavam irritação e atitudes de automutilação em

'Parasitologia Veterinária da Universidade Federal de Santa Maria, RS (UFSM). Faixa de Camobi Km 9, Prédio 20, sala 4232, 97105-900, Santa Maria, RS, Brasil. E-mail: sgmonteiro@uol.com.br. Autor para correspondência.

${ }^{2}$ Microbiologia Veterinária da UFSM, Santa Maria, RS, Brasil.

${ }^{3}$ Curso de Medicina Veterinária da UFSM, Santa Maria, RS, Brasil. 
seus hospedeiros, que arrancavam os pêlos e escarificavam a pele, na tentativa de livrarem-se dos parasitos.

Os mamíferos foram colocados em álcool $70 \%$ e posteriormente classificados conforme suas características morfológicas (TADDEI, 1997). Os insetos da ordem Siphonaptera encontrados nos hospedeiros foram armazenados em álcool $70 \%$ para posterior montagem de lâminas permanentes conforme a técnica de Costa e Lima (PINTO, 1945), visando à identificação da espécie. Esse processo foi realizado no Laboratório de Parasitologia Veterinária da Universidade Federal de Santa Maria, sendo utilizada a chave de classificação de LINARDI \& GUIMARÃES (2000).

Várias fêmeas ingurgitadas foram encontradas e identificadas como pertencentes à espécie R. pulex (Figura 1). Segundo COSTA LIMA (1943), sifonápteros desse gênero possuem maxilas relativamente longas, estreitas e curvadas para trás como representado na figura 2 .

A infestação de $\boldsymbol{R}$. pulex em $\boldsymbol{M}$. molossus no Rio de Janeiro foi relatada por ESBERARD (2001). Este autor só encontrou exemplares fêmeas, o que segundo NOWAK (1995), deve-se ao fato que, após sua alimentação, os machos abandonam o hospedeiro, não ocorrendo o mesmo com as fêmeas que permanecem fixadas, alimentando-se para maturação de seus ovos.

Pulgas, carrapatos, hemípteros e moscas são verdadeiros parasitas, pois são menores que os hospedeiros, atacando lentamente sem matar. Das cerca de 6000 espécies de parasitas externos em vertebrados de sangue quente conhecidas, 687 encontram-se parasitando morcegos (KUNZ, 1988). Conforme RYBERG (1917), os parasitas de morcegos

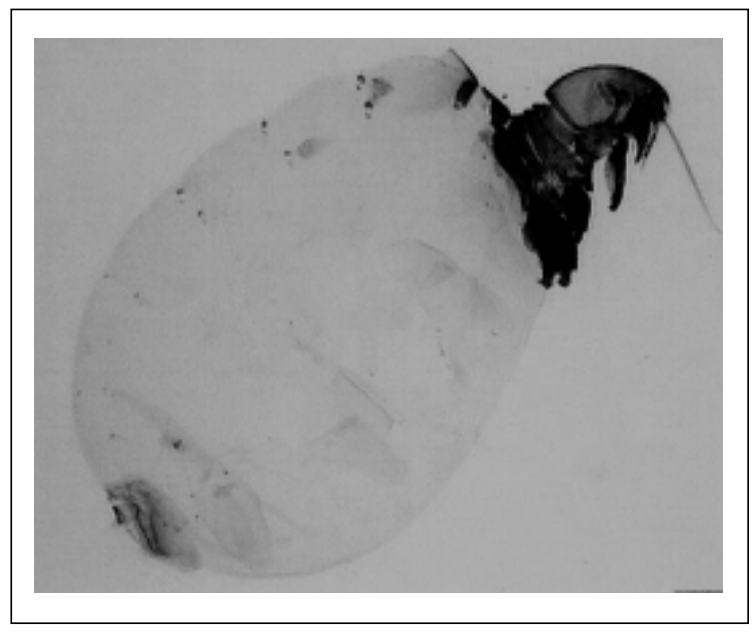

Figura 1 - Fêmea de Rhynchopsyllus pulex.

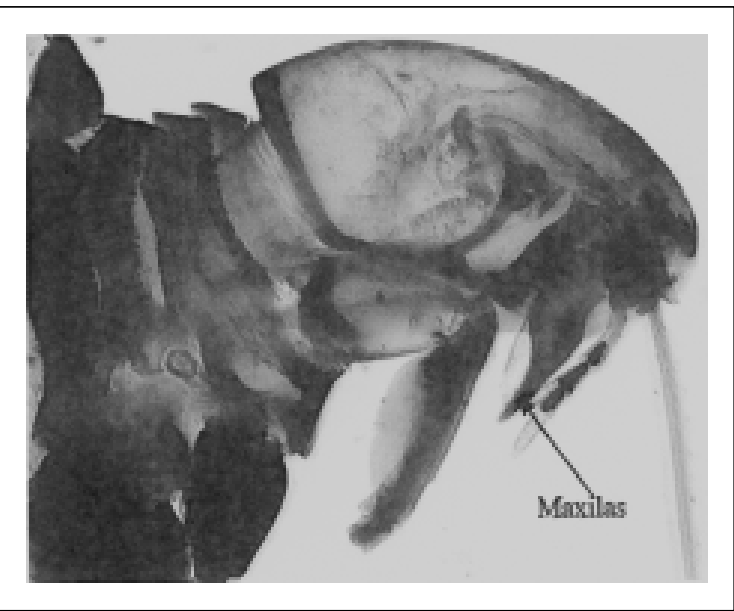

Figura 2 - Parte anterior do corpo de Rhynchopsyllus pulex.

são muito numerosos e mostram curiosas adaptações de vida neste hospedeiro.

A partir desse achado parasitológico, conclui-se que novas pesquisas devem ser realizadas nessa área, para estimar a participação dessa pulga quanto à sua possível atuação como veiculadora de agentes patogênicos nos diferentes elos da cadeia epidemiológica.

\section{REFERÊNCIAS}

COSTA LIMA, A. Insetos do Brasil. Rio de Janeiro : Escola Nacional de Agronomia, 1943. 141p. (Série didática n.5).

ESBERARD, C. Infestation of Rhynchopsyllus pulex (Siphonaptera: Tungidae) on Molossus molossus (Chiroptera) in Southestern Brazil. Memórias do Instituto Oswaldo Cruz, Rio de Janeiro, v.96, n.8, p.1169-1170, 2001

DVAS - DIRETORIA DE VIGILÂNCIA AMBIENTAL SES/GDF. Método visual para identificação de morcegos do Distrito Federal - Brasil. Capturado em 23 junho 2004. On-line. Disponível em: http://www.saude.df.gov.br/

KUNZ, T.H. Ecologic and behavioral methods for the study of bats. Washington : Smithsonian Institue, 1988. 533p.

LINARDI, P.M.; GUIMARÃES, L.R. Sifonápteros do Brasil. São Paulo : Museu de Zoologia USP, Fapesp, 2000. p.291.

NOWAK, R.M. Walker's mammals of the world. 4.ed. Baltimore : John Hopkins University, 1995. 1629p.

PINTO, C. Zoo-parasitos de interesse médico e veterinário. Rio de Janeiro : Scientífica, 1945. 461p.

RYBERG, O. Studies on bats and bats parasites. Stockholm : Bokforlaget Svensk Natur, 1917. 330p.

TADDEI, V.A. Taxonomia de morcegos. Biológico, v.59, p.85-88, 1997.

Ciência Rural, v.35, n.4, jul-ago, 2005. 